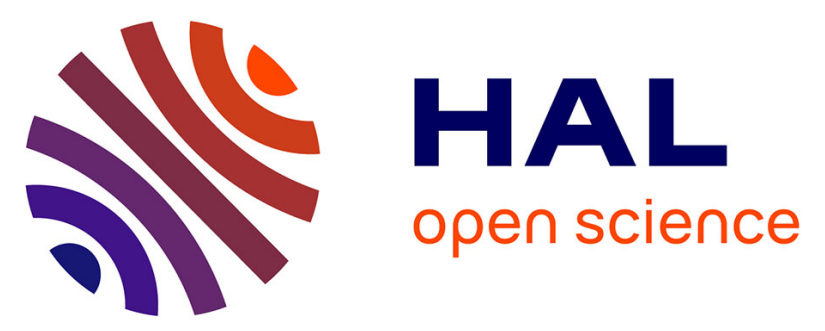

\title{
Work related asthma. A causal analysis controlling the healthy worker effect.
}

Orianne Dumas, Nicole Le Moual, Valérie Siroux, Dick Heederik, Judith

Garcia-Aymerich, Raphaëlle Varraso, Francine Kauffmann, Xavier Basagaña

\section{- To cite this version:}

Orianne Dumas, Nicole Le Moual, Valérie Siroux, Dick Heederik, Judith Garcia-Aymerich, et al.. Work related asthma. A causal analysis controlling the healthy worker effect.. Occupational and Environmental Medicine, 2013, 70 (9), pp.603-10. 10.1136/oemed-2013-101362 . inserm-01324289

\section{HAL Id: inserm-01324289 https://www.hal.inserm.fr/inserm-01324289}

Submitted on 31 May 2016

HAL is a multi-disciplinary open access archive for the deposit and dissemination of scientific research documents, whether they are published or not. The documents may come from teaching and research institutions in France or abroad, or from public or private research centers.
L'archive ouverte pluridisciplinaire HAL, est destinée au dépôt et à la diffusion de documents scientifiques de niveau recherche, publiés ou non, émanant des établissements d'enseignement et de recherche français ou étrangers, des laboratoires publics ou privés. 


\section{Work related asthma.}

\section{A causal analysis controlling the healthy worker effect.}

Orianne Dumas ${ }^{1,2}$, Nicole Le Moual ${ }^{1,2}$, Valérie Siroux ${ }^{3,4}$, Dick Heederik ${ }^{5}$, Judith GarciaAymerich ${ }^{6,7,8,9}$, Raphaëlle Varraso ${ }^{1,2}$, Francine Kauffmann ${ }^{1,2}$, Xavier Basagaña ${ }^{6,7,8}$

1. Inserm, Center for research in Epidemiology and Population Heatlh (CESP), U1018, Respiratory and Environmental Epidemiology team, F-94807, Villejuif, France

2. Univ Paris-Sud 11, UMRS 1018, F-94807, Villejuif, France

3. Inserm U823, Centre de recherche Albert Bonniot, La Tronche, France

4. Université Joseph Fourier, Grenoble, France

5. IRAS, Division of Environmental Epidemiology, Utrecht University, Utrecht, Netherlands

6. Centre for Research in Environmental Epidemiology (CREAL), Barcelona, Spain

7. IMIM (Hospital del Mar Research Institute), Barcelona, Spain

8. CIBER en Epidemiologia y Salud Pública (CIBERESP), Barcelona, Spain

9. Department of Experimental and Health Sciences, Universitat Pompeu Fabra, Barcelona, Spain

\section{Corresponding author:}

Orianne Dumas

Respiratory and environmental Epidemiology, CESP/U 1018 Inserm

16, avenue Paul Vaillant Couturier

94807 Villejuif Cedex, France

Email: orianne.dumas@inserm.fr

Tel: +33145595357 / Fax: +33145595169 


\section{Funding:}

French Agency of health safety, environment and work (AFSSET-EST-09-15); Hospital program of clinical research (PHRC)-Paris; National Research Agency - Health environment, health-work program (ANR-SEST 2005); National Research Agency (ANR- 2010-PRSP003); Merck Sharp \& Dohme (MSD); Isere committee against respiratory diseases (COMARES); French Ministry of foreign and European affairs / Netherland organization for scientific research (NWO) Van Gogh program for French Dutch cooperation; and the University Paris Sud 11 - ED420 doctoral grant.

Total word count: 4148

Keywords: Healthy worker effect, Marginal structural models, Asthma. 


\section{ABSTRACT}

Objectives: The healthy worker effect usually leads to underestimation of the association between occupational exposure and asthma. The role of irritants in work-related asthma is disputed. We estimated the effect of occupational exposure on asthma expression in a longitudinal study, using marginal structural modeling to control for the healthy worker effect.

Methods: Analyses included 1284 participants (17-79 years, 48\% men) from the follow-up (2003-2007) of the French Epidemiological study on the Genetics and Environment of Asthma (EGEA, case-control study). Age at asthma onset, periods with/without attacks over lifetime and occupational history were recorded retrospectively. Exposures to known asthmagens, irritants or low level of chemicals/allergens were evaluated through a jobexposure matrix. The job history was reconstructed into 5-year intervals.

Results: Thirty-one percent of subjects had ever been exposed to occupational asthmagens. Among the $38 \%$ of subjects who had asthma (ever), presence of attacks was reported in $52 \%$ of all time-periods. Using standard analyses, no association was observed between exposure to known asthmagens (Odds-Ratio $(95 \% \mathrm{CI})$ : $0.99(0.72-1.36))$ or to irritants/low level of chemicals/allergens $(0.82(0.56-1.20))$ and asthma attacks. Using a marginal structural model, all associations increased with suggestive evidence for known asthmagens (1.26 (0.90 - 1.76)), and reaching statistical significance for irritants/low level of chemicals/allergens $(1.56(1.02-2.40))$.

Conclusion: The healthy worker effect has an important impact in risk assessment in workrelated asthma studies. Marginal structural models are useful to eliminate imbalances in exposure due to disease-driven selection. Results support the role of irritants in work-related asthma. 
Abstract word count: 250

What this paper adds

- The current study uses a novel methodology from the field of causal inference, to control for the healthy worker effect, to estimate the relationship between workplace exposures and asthma clinical expression over the lifetime.

- Our findings show that the healthy worker effect has an important impact in risk assessment in work-related asthma studies.

- The role of moderate exposure to irritants in work-related asthma may have been underestimated in the past and should receive more consideration. 


\section{INTRODUCTION}

It is well-recognized that workplace exposures importantly contribute to new-onset and to exacerbation of asthma. ${ }^{1-4}$ More than 350 agents have already been recognized to cause asthma, ${ }^{3}$ and new agents are reported each year. ${ }^{5}$ Most occupational asthmagens are low or high molecular weight sensitizers, but irritant exposures are receiving increasing attention. ${ }^{67}$ The healthy worker effect (HWE) is a challenging issue ${ }^{8}$ that may obscure evidence for the role of new hazards, and may particularly affect the study of work-related asthma. ${ }^{9}$ It results from the phenomenon that asthma or related symptoms may influence job choice through the avoidance of potentially hazardous occupational exposure, ${ }^{9-12}$ through an initial ("hire effect") or an ongoing ("survivor effect") selection process. In the former, subjects with asthma before entering the workforce may select at first hire a work environment without hazardous exposures; in the latter, exposed workers experiencing new-onset or exacerbation of a preexisting asthma may decide to move to a non-exposed job. At the epidemiological level, the consequence of the HWE is an underestimation of the associations between occupational exposure and the disease. ${ }^{13}$ The HWE bias affects both mortality and morbidity studies ${ }^{813}$ through different mechanisms that vary according to study design and the outcome of interest. Few methods have been proposed to address it in morbidity studies. ${ }^{813}$

Studying the impact of exposure on the time-varying clinical expression of the disease (e.g. asthma activity, severity, or other phenotypes) is relevant to evaluate the burden of the disease and to determine the causal agents and their mechanisms. In the presence of HWE, a study of the effect of occupational exposure on asthma expression using traditional methods may provide biased results, because of the inter-relationships over time between asthma clinical expression and occupational exposures (Figure 1). 
Emerging causal inference methods, such as marginal structural models (MSMs), ${ }^{14}$ are increasingly used to evaluate causal relationships correctly in such settings. ${ }^{15}$ They are useful when complex inter-relationships over time are present between the confounders and the variables of interest (e.g, when studying the effect of physical activity and obesity on health outcomes). ${ }^{16}{ }^{17}$ MSMs have also been used to deal with situations of "reverse causation", e.g. confounding by indication or disease severity when evaluating the effect of a therapy. ${ }^{18} 19$ Despite the strong potential of MSMs for sensible applications in medical research, their use in occupational or in respiratory epidemiology remains scarce.

In the setting of the Epidemiological Study on the Genetics and Environment of Asthma (EGEA), we aimed to study the effect of occupational exposure on asthma expression using longitudinal data, while controlling for the HWE using a MSM. In addition, we assessed the magnitude of bias due to the HWE by comparing results of the MSM with a standard analysis. 


\section{MATERIAL AND METHODS}

\section{Population}

EGEA is a French study (initial survey: 1991-1995), including asthma cases recruited in chest clinics, their first-degree relatives, and population-based controls $(2,047$ participants $),{ }^{20}$ with a follow-up in 2003-2007. ${ }^{21}$ The protocol was approved by the institutional ethics committee and all participants gave written informed consent. For the current analysis, we used information from the follow-up data regarding occupation, smoking habits and asthma history, available for 1,284 adults (Figure 2).

\section{Asthma history}

Subjects classified with asthma were cases recruited at baseline ascertained according to a standardized procedure $^{20}$ as well as family members or controls who answered positively to one of two standardized questions ("have you ever had attacks of breathlessness at rest with wheezing?"; "have you ever had asthma attacks?") at any survey, as previously described. ${ }^{21}$ Table E1 shows clear different patterns between subjects with and without asthma regarding lung function tests, skin prick tests to 12 aeroallergens and total serum Immunoglobulin E, evaluated at follow-up with a medical examination.

Age at asthma-onset was defined by taking into account the age at first asthma attack reported on both surveys. ${ }^{11}$ At follow-up (EGEA2), information regarding the presence or absence of asthma attacks over the lifetime was recorded in subjects with asthma with questions regarding the ages of disappearance/reappearance of attacks: "When was your most recent attack of asthma?"; "Have you ever had a period of several years without asthma attacks?", and if yes: “At what age did the attacks disappear/reappear?". These questions were used to 
evaluate the asthma clinical expression over the whole lifetime, for successive 5-year periods (described below) in 3 levels: "never asthma"/“ever asthma without attacks during the period"/“ever asthma with attacks during the period" (see example Figure E1).

Subjects with any inconsistency in the reported dates were checked case by case using the scanned questionnaires. Corrections were made (after checking files) for $12 \%$ of the subjects. A total of 109 subjects with asthma had missing data for asthma history variables: 42 had missing data for age at asthma onset, and 67 for retrospective question regarding presence / absence of attacks over life (Figure 2). Among them, 25 were subjects who did not answer the asthma questionnaire at EGEA2 (comprising the questions regarding history of asthma attacks), because they answered inconsistently to the main asthma questions (used to define ever asthma) between EGEA1 and EGEA2 ("yes" at EGEA1 and "no" at EGEA2). Comparison of the subjects with asthma with and without missing data for asthma history over the lifetime is presented in Table E2.

\section{Occupational history}

A complete occupational history was recorded by questionnaire in a face-to-face interview, with information regarding position, industry, job tasks and calendar year (or age) at beginning and end of the occupation. All training periods with duration of at least 1 month, and all jobs with duration of at least 3 months were recorded.

A four-digit code (International Standard Classification of Occupations 1988) was assigned by an experienced coder. ${ }^{11}$ Occupations (jobs and training periods) were linked to estimates of exposure to 22 agents using an asthma-specific job-exposure matrix (JEM). ${ }^{22}$ This JEM has been set up in the context of the EGEA baseline study, ${ }^{22}$ and has largely been used in the literature (http://cesp.vjf.inserm.fr/asthmajem). The JEM was first merged on job codes to 
evaluate exposure (yes/no) to each of the 22 agents for each reported job. To improve exposure assessment, the JEM application included an occupational hygiene expert reevaluation step: individual (job by job) re-evaluation of exposure was conducted by 3 occupational hygiene experts, ${ }^{23}$ for some jobs considered as needing a check (for instance, when exposures differ greatly by industry, or when job codes are not precise enough). ${ }^{22}$ Exposures to (i) 18 known asthmagens, and (ii) 4 work environments with exposure to irritants, or with low level of exposure to chemicals or allergens, were evaluated. Examples of the most frequent occupational asthmagens estimated by the JEM are: latex, bio-aerosols, highly reactive chemicals, industrial cleaning agents, metal sensitizers, metal working fluids environments and textile production (exhaustive list of exposures at: http://cesp.vjf.inserm.fr/asthmajem/matrixtable.htm).

When several occupations were reported over the same period, the occupation with the maximum exposure level during the overlap was chosen. For subjects with complex overlaps, file by file checking using the scanned questionnaires and sometimes additional information written by the interviewer was performed for $7 \%$ of the subjects.

Job history information was used to create a dataset which assessed occupational exposure at regular intervals (5 years), with the time of the first occupation for each subject as starting point, and follow-up up to time of the second survey or of the last reported occupation (Figure E1). At each 5-year period, exposure was defined as the maximum exposure level of the subject over the period: "non exposed”/“"exposed to irritants or low level chemicals/allergens only"/“exposed to known asthmagens". 


\section{Other covariates}

Smoking status at each period was determined using retrospective questions about ages at smoking initiation and at quitting smoking, available at EGEA1 and EGEA2. Cohort (year of birth) was included in the analyses as a categorical variable (5 categories).

\section{Statistical analyses}

Two analyses were conducted to estimate associations between occupational exposure and asthma clinical expression at each time-point: (i) a "standard" method and (ii) a marginal structural model to control for the HWE. The impact of the HWE was assessed by comparing qualitatively the odds ratios (ORs) observed in both analyses.

\section{Standard analyses}

A longitudinal analysis (for repeated measures) was performed using data over the lifetime, divided in 5-year intervals. The outcome was asthma clinical expression. Associations between occupational exposure at each time-point and asthma expression were assessed by a pooled multinomial logistic model, adjusted for gender, smoking habits, cohort, age at first hire and time-period (number of the 5-year period, continuous variable).

\section{Marginal Structural Model}

The HWE implies that once an individual develops asthma, he is less prone to be exposed. Thus, subjects with asthma are "over-represented" in the non-exposed jobs. MSMs address this issue by weighting individuals ${ }^{14} 18$ to create a "pseudo-population" where imbalances in exposure due to asthma-driven selection are eliminated at each time-point. Thus, a MSM allows estimating what the association between exposure and asthma expression would have been if subjects with and without asthma had the same probability of exposure. 
Application of the MSM required two steps. In the first step, the weights that were assigned to each individual were estimated. The weights are proportional to the inverse of the probability that each subject had his own exposure history at a given time ( $s^{\text {th }}$ time-period), assuming it depended on previous asthma, occupational exposure history and a set of socio-demographic factors. These probabilities were estimated through "exposure models", i.e. multinomial logistic regression models for the probability of occupational exposure at each time $s$. Separate models were fitted for time $s=1$ (first job period - model A), and for times $s>1$ (pooled model - model B). ${ }^{24}$ Results from exposure models A and B are presented in Table 2 as they provide indication regarding the amount of initial selection ("hire effect", model A) and ongoing selection ("survivor effect", model B) and regarding the determinants of occupational exposure. The predicted probabilities from the exposure models for occupational exposure were used to calculate a weight for each subject at each time period, defined as the product of all time-specific inverse probabilities of exposure up to that time period (see online supplement). To avoid large variation in weights, we used stabilized weights as recommended. ${ }^{14}$

The second step consisted in estimating the effect of occupational exposure on asthma expression in the reweighted pseudo-population using a weighted pooled multinomial logistic model for asthma expression at period ( $(s)$ according to occupational exposure at period $(s)$.

The estimated weight distribution may serve as indicator of a potential bias in the exposure model. Though no precise numeric criteria have been defined yet, "well-behaved" weights have a mean close to 1 and a "small range". ${ }^{25}$ As a sensitivity analysis, we evaluated whether associations observed with the MSM may be driven by a small number of individuals with an extreme weight (intuitively, associations may be biased if a few subjects are assigned a weight disproportionally large or small). For this purpose, we used weight truncation, i.e. we reset the 
value of weights greater (lower) than $99^{\text {th }}\left(1^{\text {st }}\right)$ percentile to the percentile value. ${ }^{25}$ When weights are truncated, associations observed using the MSM are expected to be closer to those observed with a standard model, as the confounding induced by the HWE is less controlled. Other sensitivity analyses using time-periods shorter than 5 years are presented in online supplement. 


\section{RESULTS}

Study participants had an average age of 44.6 years at follow-up and $48 \%$ were men. After dividing occupational histories in 5-year intervals, the dataset consisted in 6,329 personperiods. A description of the subjects' work history is provided in online supplement. Clinical and socio-demographic characteristics varied with cohort (Table 1). Among the $38 \%$ of subjects who had asthma (ever), presence of attacks was reported in $52 \%$ of all time-periods (see clinical characteristics in Table E1). Thirty-one percent of the subjects had ever been exposed to asthmagens (most frequent exposures: highly reactive chemicals (44\%), latex $(28 \%)$, metals $(19 \%)$ and industrial cleaning products $(18 \%))$. Twenty percent of the subjects had ever been exposed to irritants or low level exposure to chemicals/allergens (and not to "known asthmagens"). Among them, 78\% were exposed to low level of chemicals/allergens, and $51 \%$ were exposed to irritants (34\% exposed to both).

\section{Exposure models}

Results from the "exposure models", used in the first step of the application of MSM to estimate the weights, are presented in Table 2. Results from exposure model A show the factors predicting occupational exposure at the first job period. Asthma before first hire was not a predictor of exposure at the first period (indicating absence of a "hire effect"). Results from exposure model B show the factors predicting occupational exposure at the remaining time-periods (time period $>1$ ). Given past occupational exposure, subjects with asthma were less likely to be exposed to asthmagens in the following period (OR (95\% Confidence Interval): $0.74(0.50-1.12))$, and significantly less likely to be exposed to irritants and low level of chemicals/allergens $(0.59(0.37-0.93))$, indicating the presence of a "survivor effect". 


\section{Standard and marginal structural model for asthma expression and exposure at each time-point}

Using a standard model, occupational exposures at each period were not positively associated $($ ORs $<1)$ with asthma with or without attacks during the period (Figure 3). Using the MSM, an OR of $1.26(0.90-1.76)$ was observed for exposure to asthmagens, compared to an OR of $0.99(0.72-1.36)$ observed in the standard model. Exposure to irritants or low level of chemicals/allergens were associated with asthma with presence of attacks (OR: 1.56 (1.022.40)), compared to an OR of $0.82(0.57-1.20)$ observed in the standard model.

In the current analysis, the mean of the weights was 1.02 , the range was $(0.08 ; 8.81)$ and the $1^{\text {st }}$ and $99^{\text {th }}$ percentiles were $(0.39 ; 2.26)$. When extreme weights were truncated, the OR for exposure to irritants or low level of chemicals/allergens and asthma with presence of attacks decreased to $1.39(0.93-2.10)$, and the odds-ratio for asthmagens remained similar (1.22 (0.88$1.70))$.

For the association between exposure to irritants or low level of chemicals/allergens and asthma without attacks during the period, in the standard model, a significant negative association was observed $(0.53(0.33-0.83))$. In the MSM, an elevated OR (1.45), with a wide confidence interval (0.81-2.62) was observed. However, when extreme weights were truncated, no association was observed (OR: 1.01), indicating that the value of 1.45 may have been driven by a small number of individuals with an "extreme" weight value. 


\section{DISCUSSION}

The bias due to the HWE has an important impact in risk assessment in epidemiological studies of work-related asthma. Results showed that this bias explained for a substantial part the lack of associations between occupational exposure and asthma expression when standard methods were used. Standard analyses evidenced no positive associations between exposure to known asthmagens and asthma expression over a lifetime (OR: 0.99). After controlling for the HWE using a MSM, the OR increased to 1.26. In addition, a positive association was observed using MSM between asthma expression and exposure to irritants or low level of chemicals/allergens (OR: 1.56), which were previously classified as at "low risk" for asthma. ${ }^{22}$ The current study shows that the use of MSMs allows improving control for the HWE in a longitudinal study of work-related asthma.

The presence of a HWE in studies on asthma has been described, ${ }^{9-12}$ but the current study is the first extensive evaluation of the magnitude of its impact on the associations between occupational exposure and asthma. The study design (inclusion of child and adult cases recruited in chest clinics) makes the EGEA study prone to a HWE because of the high proportion of subjects with childhood-onset asthma, and/or with a severe form of the disease. ${ }^{20}$ However, the HWE likely affects the results of many studies since a hire effect has been observed for asthma or related phenotypes in two other European population-based studies $^{10} 12$ and a survivor effect was observed in various population-based studies or occupational cohorts. ${ }^{9}$

In the current study, the HWE might be underestimated due to lack of information regarding asthma characteristics across a lifetime period. Our results regarding the survivor effect were consistent with the literature. ${ }^{9}$ However, we did not observe a "hire effect" although such an 
effect was observed in a previous prospective study ${ }^{11}$ in the EGEA population, including 298 subjects examined as a child at the first survey, and who had started work at follow-up. In that previous analysis, a hire effect in subjects with severe asthma in childhood was observed. In the current analysis, using retrospective information, asthma characteristics such as severity were not available for the entire lifetime. Socio-economic changes between 1945 and 2000 may also explain the different results of both analyses. Hypotheses regarding the sociodemographic determinants of the HWE include the amount of employment choice, influenced by both individual characteristics (gender, social class, etc.) and the socio-economic context. ${ }^{9}$ Clinical characteristics (asthma severity, age at onset) also vary with cohort in EGEA, partly due to the study design, making hard to determine whether the selection phenomenon truly varies with cohort or mostly depends on clinical characteristics. Cohorts of larger size and more homogenous in age would be needed to study such hypotheses.

Few methods have been proposed to reduce the HWE in morbidity studies. ${ }^{913}$ When detailed information is available regarding the time course of asthma onset or exacerbations, the HWE is attenuated or absent when using an appropriate time-windows for exposure, e.g. the job held before/at first occurrence or re-activation of the disease, ${ }^{22}{ }^{26}$ but this method is limited to studies focused on the occurrence of one specific event. However, asthma expression is highly variable over a lifetime, and the disease is increasingly divided into sub-phenotypes, some of which remain poorly understood..$^{27}$ Longitudinal studies recording prospectively occupational exposures and asthma characteristics, including time-varying parameters (symptoms, biological features, etc.), at several time-points, are needed to better understand the determinants of asthma and its heterogeneity over a lifetime. In such studies, even if detailed information is available, a specific method that takes the HWE into account has to be implemented, while conventional methods may lead to biased results. Using causal inference 
methods such as MSMs may allow improving the control of this bias when studying the effect of current exposure as well as cumulative exposure. In particular situations, when only the effect of current exposure is of interest, simple adjustment for past exposure history and past asthma history may also be considered (see online supplement for more details).

To our knowledge, this is the first time a MSM is used to address the HWE. Different types of bias related to the HWE exist, which depend on the study design (e.g. population-based or case-control studies vs. occupational cohort studies) and the outcome of interest (e.g. mortality or morbidity studies). For instance, in occupational cohort studies, the tendency by less healthy workers to leave employment generates a survivor effect. In this situation, the relationship between cumulative exposure and the outcome is confounded by the time-varying work status, used as a surrogate of an unmeasured poor health condition. ${ }^{28}$ It has been shown that in such situation, MSMs are not appropriate. ${ }^{142529}$ This is because for one level of the confounder (unemployment) all subjects are by definition unexposed (this violates the “positivity assumption", see online supplement for more details). Other causal models (gestimation) have recently been used to address the survivor effect in this different context. ${ }^{30}$ In the current case-control study, we were interested in asthma as a specific condition leading to a move to a non-exposed job. Thus, asthma was the confounder of interest. As not all subjects with asthma move to non-exposed jobs, all possible categories of exposure can be observed at each level of the confounder. This property allows the use of a MSM in our case. We do not consider that it is needed to take into account employment status in the current study, because unemployment (as a rough proxy for a poor health condition) is unlikely to have a major independent effect on asthma expression. ${ }^{31}$ In addition, as in all analyses, the validity of the results requires no unmeasured confounding. Although this possibility can never be ruled out, we have included the confounders usually used in the literature to study the relationships 
between occupational exposure and asthma. The weight distribution (mean close to one, moderate range) was not indicative of bias in the exposure models. ${ }^{25}$ Finally, the EGEA study combines a case-control and a longitudinal design. Though this study design is atypical for the application of a MSM, we analyzed the data as a cohort study based on a non-representative sample (and the case-control status was not our response variable).

After correcting, at least partially, for the HWE, the results suggested elevated risks of asthma attacks associated not only with known asthmagens, but also, and in a more pronounced way, with exposure to other agents, whose role in asthma is less established. They include possible exposure to asthmagens (i.e. low probability of enough exposure to cause occupational asthma) or moderate (not high peak) exposure to irritants (exhaust fumes, environmental tobacco smoke, or others). ${ }^{22}$ This category of exposure regroups several various jobs, including cooks, cleaners, mechanics, waiters, drivers, etc. At the time the JEM was designed in $2000,{ }^{22}$ based on a list of 150 substances inducing occupational asthma established in 1993 , these agents were classified as "at low risk" for asthma based on current knowledge. Now, the role of repeated exposure to irritants, even at low level, in both asthma onset and exacerbations is increasingly discussed. ${ }^{1632}$ Concurrently, it has been shown that the part of asthma related to atopy, or attributable to allergen exposure would be less than $50 \%{ }^{33}$ It is now considered that asthma consists of multiple phenotypes, ${ }^{27}$ and irritant-induced asthma remains poorly understood. ${ }^{3634}$ It has been questioned whether asthma may be due to lowlevel irritants exposures alone or combined with allergen exposure. ${ }^{7}$ Some jobs classified as exposed to irritants were concurrently classified as possibly exposed to low level of asthmagens, and power issues prevented the disentangling of these two effects in the current study. The survivor effect appeared stronger for irritants or low level of chemical/allergens, consistently with our hypothesis that avoidance of exposure is not specific and may impact 
overall exposure to classical dusts, gases and fumes. ${ }^{11}$ Less healthy people are likely to avoid exposures they expect to cause asthma symptoms, which are not necessarily exposures known by clinicians and researchers to cause asthma. Controlling for the HWE may be important to correctly evaluate the role of irritant exposures in asthma.

Our results should be interpreted with caution. The retrospective assessment of lifetime events was a limitation. Regarding occupational history, precise information was registered and exposure was estimated by a JEM, limiting recall bias. ${ }^{35}$ This JEM has been used efficiently several times before to evaluate associations between occupational exposure and asthma. ${ }^{22} 26$ ${ }^{36}$ The main limitation was the retrospective assessment of asthma history: asthma activity or more precise phenotypes all over the lifetime could not be assessed as only restricted information was available. Five-year time-periods were chosen to take into account uncertainties in the report of the age of the studied events. Yet, the available data regarding asthma expression history are crude and a non-differential misclassification bias may affect the results; this likely explains in part why the observed associations do not reach statistical significance in the MSM, even for known asthmagens, and preclude strong conclusions. Finally, the choice of wide time-intervals (5-year) to study the relationship between current exposure and current asthma expression implies that over each time-period the outcome (appearance of asthma attacks) may precede the exposure. However, it is unlikely that a reverse causation explains the observed associations as asthma symptoms are not expected to lead to an increased future exposure level. Thus we believe the use of wide time interval mainly raises the issue of non-differential misclassification. Despite the mentioned limitations, positive associations were observed only with the MSM, indicating that the absence of association observed in standard models was at least partly explained by the HWE. 
Applications of MSM in other studies with a prospective design and repeated data are needed to draw stronger conclusions.

Our results have several implications for researchers and clinicians in the field of occupational respiratory diseases. First, the role of irritants in asthma onset and exacerbation should receive more consideration, in research to better determine their effects and mechanisms, and in clinical practice when considering the possible causal agent in patients with asthma. Second, our results imply considerations regarding future epidemiological studies on work-related asthma, other respiratory or allergic disorders or, more generally, in morbidity studies involving endpoints sensitive to the HWE. As the HWE may importantly bias risk estimates in such studies, it has to be anticipated when designing and choosing the methodological strategies. Results support a broader use of causal inference methods, which have great potential to delineate complex relationships, especially those involving time-dependent events. Regardless of the chosen statistical method, well-designed studies with precise information regarding time-varying asthma expression and phenotypes and all occupational history are crucial. ${ }^{9}$ 


\section{Acknowledgments}

EGEA cooperative group:

Coordination: F Kauffmann; V Siroux (epidemiology) F Demenais (genetics); I Pin (clinical aspects); R Nadif (biology).

Respiratory epidemiology: Inserm U 700, Paris M Korobaeff (Egea1), F Neukirch (Egea1); Inserm U 707, Paris : I Annesi-Maesano ; Inserm CESP/U 1018, Villejuif : F Kauffmann, N Le Moual, R Nadif, MP Oryszczyn ; Inserm U 823, Grenoble: V Siroux

Genetics: Inserm U 393, Paris: J Feingold; Inserm U 946, Paris: E Bouzigon, F Demenais, MH Dizier; CNG, Evry: I Gut (now CNAG), M Lathrop (now CEPH/Mc Gill).

Clinical centers: Grenoble: I Pin, C Pison; Lyon: D Ecochard (Egea1), F Gormand, Y Pacheco; Marseille: D Charpin (Egea1), D Vervloet; Montpellier: J Bousquet; Paris Cochin: A Lockhart (Egea1), R Matran (now in Lille); Paris Necker: E Paty, P Scheinmann; ParisTrousseau: A Grimfeld, J Just.

Data and quality management: Inserm ex-U155 (Egea1): J Hochez; Inserm CESP/U 1018, Villejuif: N Le Moual, Inserm ex-U780: C Ravault; Inserm ex-U794: N Chateigner;

Grenoble: J Ferran.

The authors thank all those who participated to the setting of the study and on the various aspects of the examinations involved: interviewers, technicians for lung function testing and skin prick tests, blood sampling, IgE determinations, coders, those involved in quality control, data and sample management and all those who supervised the study in all centers. The authors are grateful to the three CIC-Inserm of Necker, Grenoble and Marseille who supported the study and in which subjects were examined. They thank G. Vasseur (Inserm U780, Villejuif, France) for job coding. They are indebted to all the individuals who participated without whom that study would not have been possible. Finally, the authors thank one anonymous reviewer for his/her suggestions which pushed to discuss the scope of the method. 


\section{REFERENCES}

1 Henneberger PK, Redlich CA, Callahan DB, et al. An official american thoracic society statement: work-exacerbated asthma. Am J Respir Crit Care Med 2011;184:368-78.

2 Torén K, Blanc PD. Asthma caused by occupational exposures is common - a systematic analysis of estimates of the population-attributable fraction. BMC Pulm Med 2009;9:7.

3 Maestrelli P, Boschetto P, Fabbri LM, et al. Mechanisms of occupational asthma. $J$ Allergy Clin Immunol 2009;123:531-42;

4 Malo JL, Chan-Yeung M. Agents causing occupational asthma. J Allergy Clin Immunol 2009;123:545-50.

5 Pralong JA, Cartier A, Vandenplas O, et al. Occupational asthma: new low-molecularweight causal agents, 2000-2010. J Allergy (Cairo) 2012;2012:Article ID 597306, 10 pages.

6 Labrecque M. Irritant-induced asthma. Curr Opin Allergy Clin Immunol 2012;12:1404.

7 Tarlo SM, Malo JL. An official ATS proceedings: asthma in the workplace: the Third Jack Pepys Workshop on Asthma in the Workplace: answered and unanswered questions. Proc Am Thorac Soc 2009;6:339-49.

8 Pearce N, Checkoway H, Kriebel D. Bias in occupational epidemiology studies. Occup Environ Med 2007;64:562-8.

9 Le Moual N, Kauffmann F, Eisen EA, et al. The healthy worker effect in asthma: work may cause asthma, but asthma may also influence work. Am J Respir Crit Care Med 2008;177:4-10.

10 Butland BK, Ghosh R, Strachan DP, et al. Job choice and the influence of prior asthma and hay fever. Occup Environ Med 2011;68:494-501.

11 Dumas O, Smit LA, Pin I, et al. Do young adults with childhood asthma avoid occupational exposures at first hire? Eur Respir J 2011;37:1043-9.

12 Olivieri M, Mirabelli MC, Plana E, et al. Healthy hire effect, job selection and inhalation exposure among young adults with asthma. Eur Respir J 2010;36:517-23.

13 Eisen EA. Healthy worker effect in morbidity studies. Med Lav 1995;86:125-38.

14 Robins JM, Hernán MA, Brumback B. Marginal structural models and causal inference in epidemiology. Epidemiology 2000;11:550-60. 
15 Suarez D, Borras R, Basagaña X. Differences between marginal structural models and conventional models in their exposure effect estimates: a systematic review. Epidemiology 2011;22:586-8.

16 Garcia-Aymerich J, Lange P, Serra I, et al. Time-dependent confounding in the study of the effects of regular physical activity in chronic obstructive pulmonary disease: an application of the marginal structural model. Ann Epidemiol 2008;18:775-83.

17 Tager IB, Haight T, Sternfeld B, et al. Effects of physical activity and body composition on functional limitation in the elderly: application of the marginal structural model. Epidemiology 2004;15:479-93.

18 Hernán MA, Brumback BA, Robins JM. Estimating the causal effect of zidovudine on CD4 count with a marginal structural model for repeated measures. Stat Med 2002;21:1689-709.

19 Kim C, Feldman HI, Joffe M, et al. Influences of earlier adherence and symptoms on current symptoms: a marginal structural models analysis. J Allergy Clin Immunol 2005;115:810-4.

20 Kauffmann F, Dizier MH, Pin I, et al. Epidemiological study of the genetics and environment of asthma, bronchial hyperresponsiveness, and atopy: phenotype issues. Am J Respir Crit Care Med 1997;156:S123-9.

21 Siroux V, Boudier A, Bousquet J, et al. Phenotypic determinants of uncontrolled asthma. J Allergy Clin Immunol 2009;124:681-7 e3.

22 Kennedy SM, Le Moual N, Choudat D, et al. Development of an asthma specific job exposure matrix and its application in the epidemiological study of genetics and environment in asthma (EGEA). Occup Environ Med 2000;57:635-41.

23 Dumas O, Donnay C, Heederik D, et al. Occupational exposure to cleaning products and asthma in hospital workers. Occup Environ Med 2012;69:883-9.

24 Brotman RM, Klebanoff MA, Nansel TR, et al. A longitudinal study of vaginal douching and bacterial vaginosis--a marginal structural modeling analysis. Am J Epidemiol 2008;168:188-96.

25 Cole SR, Hernán MA. Constructing inverse probability weights for marginal structural models. Am J Epidemiol 2008;168:656-64.

26 Kogevinas M, Zock JP, Jarvis D, et al. Exposure to substances in the workplace and new-onset asthma: an international prospective population-based study (ECRHS-II). Lancet 2007;370:336-41.

27 Wenzel SE. Asthma phenotypes: the evolution from clinical to molecular approaches. Nat Med 2012;18:716-25. 
28 Hernán MA, Hernandez-Diaz S, Robins JM. A structural approach to selection bias. Epidemiology 2004;15:615-25.

29 Naimi AI, Cole SR, Westreich DJ, et al. A comparison of methods to estimate the hazard ratio under conditions of time-varying confounding and nonpositivity. Epidemiology 2011;22:718-23.

30 Chevrier J, Picciotto S, Eisen EA. A comparison of standard methods with Gestimation of accelerated failure-time models to address the healthy-worker survivor effect: application in a cohort of autoworkers exposed to metalworking fluids. Epidemiology 2012;23:212-9.

31 Pearce N. Methodological problems of time-related variables in occupational cohort studies. Rev Epidemiol Sante Publique 1992;40 Suppl 1:S43-54.

32 Søyseth V, Johnsen HL, Henneberger PK, et al. The incidence of work-related asthmalike symptoms and dust exposure in Norwegian smelters. Am J Respir Crit Care Med 2012;185:1280-5.

33 Douwes J, Brooks C, Van Dalen C, et al. Importance of allergy in asthma: an epidemiologic perspective. Curr Allergy Asthma Rep 2011;11:434-44.

34 Malo JL, L'Archeveque J, Castellanos L, et al. Long-term outcomes of acute irritantinduced asthma. Am J Respir Crit Care Med 2009;179:923-8.

35 De Vocht F, Zock JP, Kromhout H, et al. Comparison of self-reported occupational exposure with a job exposure matrix in an international community-based study on asthma. Am J Ind Med 2005;47:434-42.

36 Le Moual N, Siroux V, Pin I, et al. Asthma severity and exposure to occupational asthmogens. Am J Respir Crit Care Med 2005;172:440-5.

37 Kauffmann F, Dizier MH, Annesi-Maesano I, et al. [Epidemiological study of genetic and environmental factors in asthma, bronchial hyperresponsiveness and atopy.

Protocol and potential selection bias]. Rev Epidemiol Sante Publique 2001;49:343-56. 


\section{FIGURES}

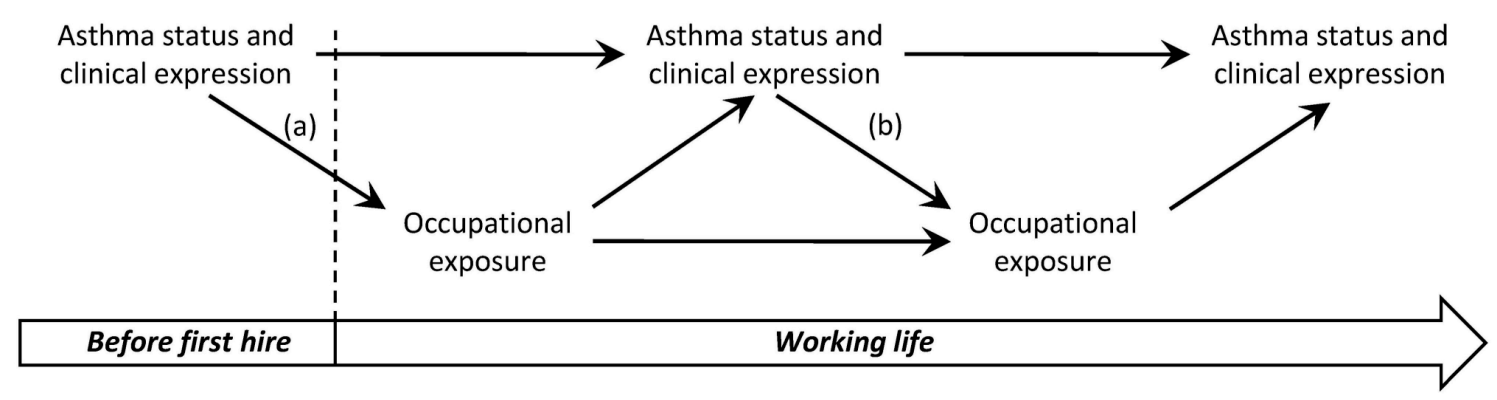

Figure 1. The time-dependent relationship between occupational exposure and asthma status and clinical expression. Occupational exposure may cause new-onset of asthma or exacerbation of a pre-existing asthma. Asthma status and clinical expression may influence subsequent occupational exposure through the avoidance of jobs with potentially hazardous exposures (healthy worker effect). The hire effect, i.e. selection occurring at entry in the workforce, is represented by arrow (a). The survivor effect, i.e. ongoing selection process throughout the working life (e.g. transfer to non-exposed jobs), is represented by arrow (b). 


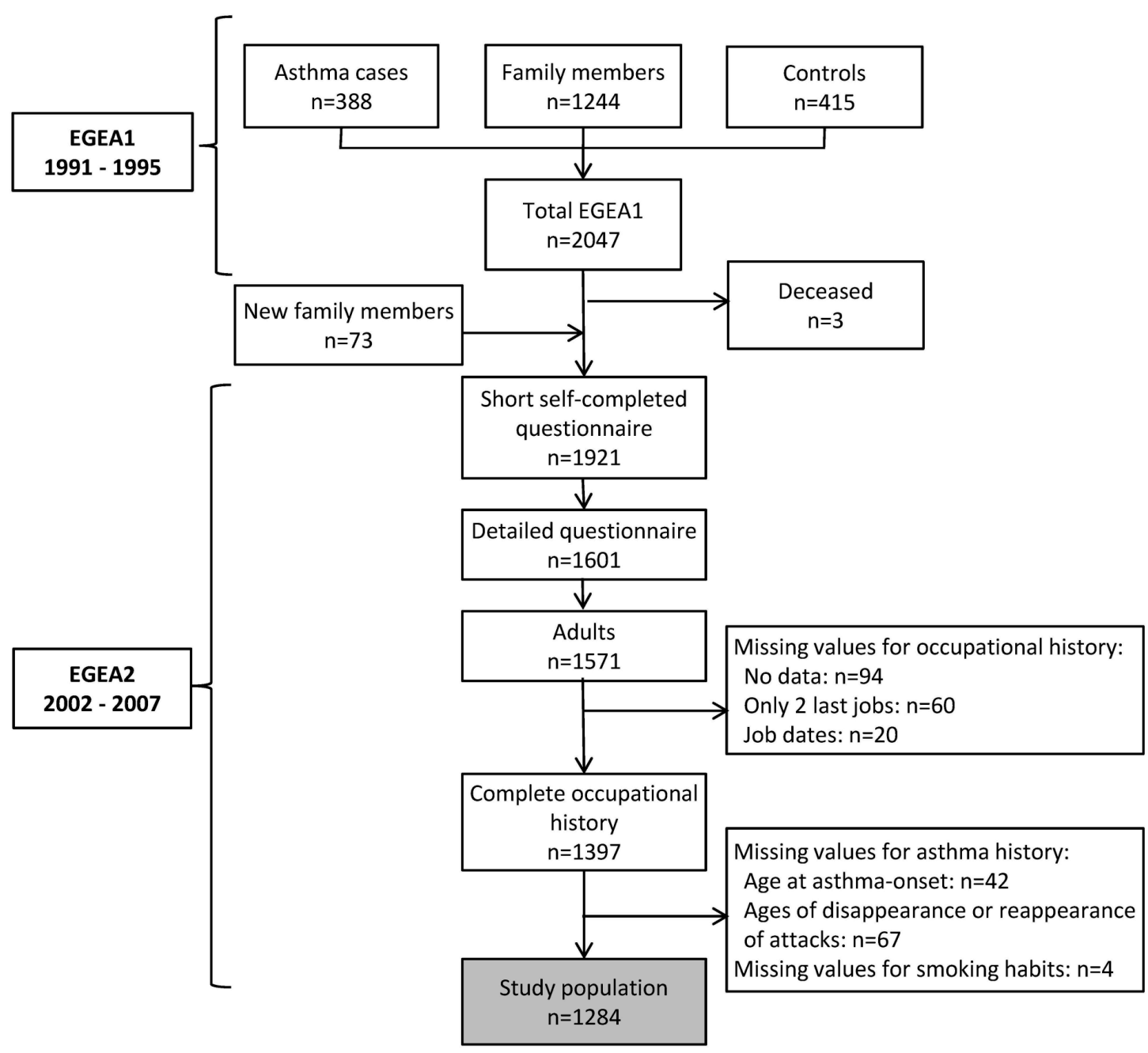

Figure 2. Flow chart of the selected population.

As explained in detail in previous publications ${ }^{2037}$, the EGEA1 cases and control participants were selected out of $\sim 6400$ potentially eligible cases and $\sim 3600$ potentially eligible controls who completed a questionnaire with 4 questions regarding asthma (>7000 questionnaires have been distributed to cases and controls). Out of them, 516 cases and 1134 controls fulfilled all inclusion criteria, and 516 cases and 1011 controls were invited to participate to the study. Factors related to participation have been published and revealed no bias pertinent for the present analysis. $^{37}$ 


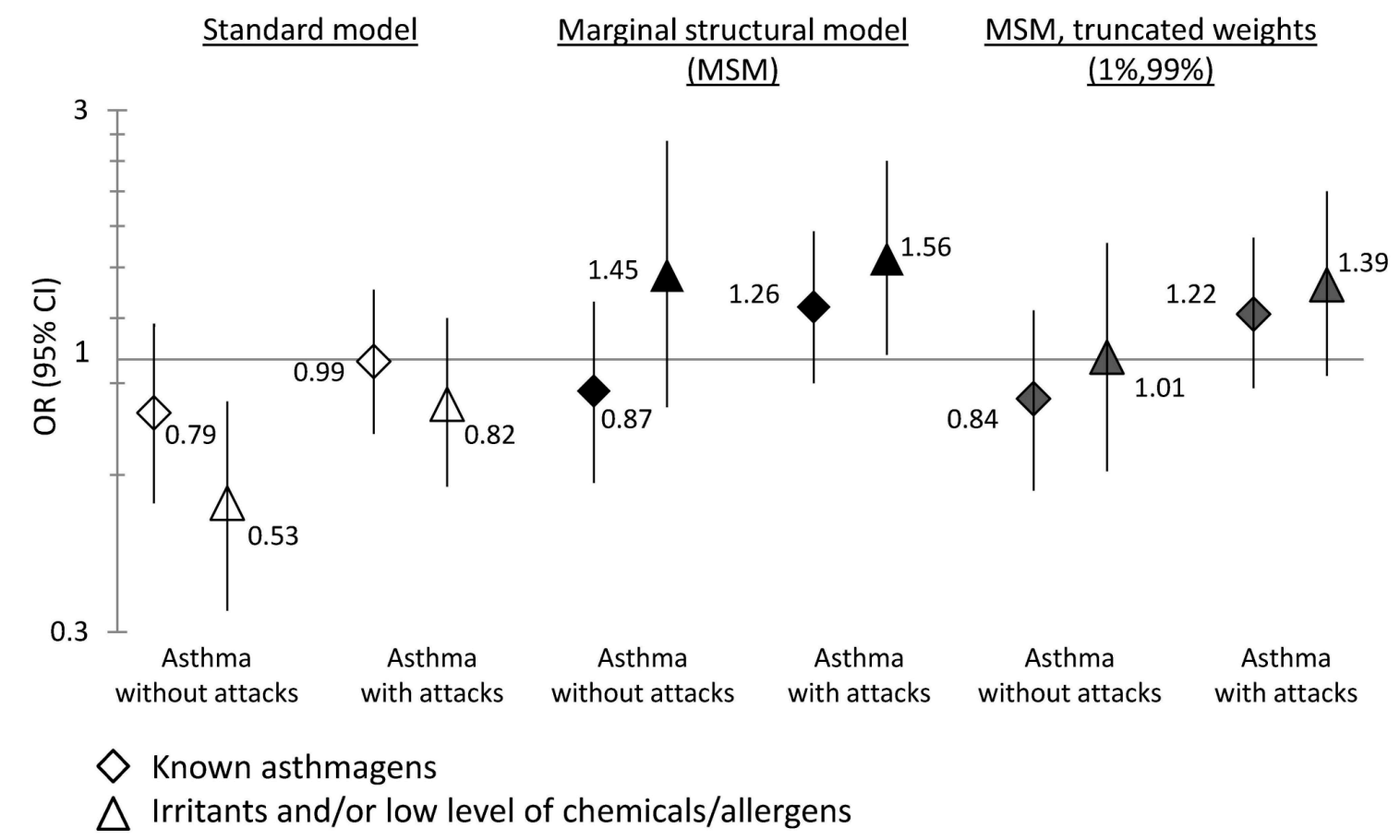

Figure 3. Results from standard and marginal structural models to estimate the effect of occupational exposure on asthma expression at each time-period.

CI, confidence interval; OR, odds-ratio.

The standard model was a pooled multinomial logistic regression of asthma expression at period $(s) v s$. occupational exposure at period (s) adjusted for time-period, age at the first hire, gender, year of birth, smoking status (results close to unadjusted values: respectively 0.71 $(0.49-1.02)$ and $0.67(0.44-1.03)$ for asthma without attacks; $1.01(0.74-1.36)$ and 0.91 $(0.65-1.27)$ for asthma with attacks).

The marginal structural model (MSM) was a weighted pooled multinomial logistic regression asthma expression at period (s) vs. occupational exposure at period (s) with adjustment for baseline covariates (age at the first hire, gender, year of birth). The MSM with truncated weights (sensitivity analysis) was the same model, using weights truncated to the $1^{\text {st }}$ and $99^{\text {th }}$ percentiles 
Table 1. Description of the population according to year of birth

\begin{tabular}{|c|c|c|c|c|c|c|}
\hline Year of birth & $\leq 1945$ & ]1945-1955] & ]1955-1965] & ]1965-1975] & $>1975$ & $\mathrm{p}$ \\
\hline $\mathrm{n}$ & 271 & 302 & 184 & 194 & 333 & - \\
\hline Number of 5-years period, mean (SD) & $7.8(2.2)$ & $7.0(1.4)$ & $5.3(1.2)$ & $3.2(0.9)$ & $1.5(0.6)$ & - \\
\hline Age at asthma onset, mean (SD) & $31.9(17.4)$ & $19.9(16.7)$ & $18.4(13.3)$ & $13.2(9.5)$ & $6.0(5.1)$ & $<0.0001$ \\
\hline Gender, $\%$ men & 52.8 & 49.7 & 35.9 & 45.4 & 51.7 & 0.003 \\
\hline \multicolumn{7}{|l|}{ Smoking status at EGEA2, \% } \\
\hline Current smoker & 8.1 & 14.9 & 20.1 & 29.4 & 37.5 & $<0.0001$ \\
\hline Age at the first hire, mean (SD) & $18.3(4.0)$ & $19.3(4.0)$ & $19.5(4.0)$ & $20.3(3.0)$ & $19.3(2.4)$ & $<0.0001$ \\
\hline \multicolumn{7}{|l|}{ Lifetime occupational exposure, $\%$} \\
\hline Non exposed & 45.4 & 47.4 & 49.5 & 47.9 & 52.6 & \multirow[t]{3}{*}{0.18} \\
\hline Known asthmagens & 36.5 & 34.4 & 29.9 & 29.4 & 25.5 & \\
\hline Irritants and/or low level of chemicals/allergens & 18.1 & 18.2 & 20.6 & 22.7 & 21.9 & \\
\hline Non exposed & 67.2 & 70.2 & 73.4 & 71.6 & 63.7 & \multirow[t]{3}{*}{0.43} \\
\hline Known asthmagens & 16.6 & 15.2 & 14.1 & 16.5 & 19.2 & \\
\hline Irritants and/or low level of chemicals/allergens & 16.2 & 14.6 & 12.5 & 11.9 & 17.1 & \\
\hline
\end{tabular}

SD, standard deviation. 
Table 2. Associations between occupational exposure and various predictors (health and socio-demographic factors) in the exposure models (used in the weights calculation)

\begin{tabular}{|c|c|c|c|c|}
\hline \multirow[t]{2}{*}{$\mathrm{n}=1,284$} & \multicolumn{2}{|c|}{$\begin{array}{l}\text { Model A: occupational exposure at time } s=1 * \\
\text { OR }(95 \% \mathrm{CI})\end{array}$} & \multicolumn{2}{|c|}{$\begin{array}{l}\text { Model B: occupational exposure at times } s>1 \dagger \\
\text { OR }(95 \% \mathrm{CI})\end{array}$} \\
\hline & Known asthmagens & $\begin{array}{l}\text { Irritants and/or low level } \\
\text { of chemicals/allergens }\end{array}$ & Known asthmagens & $\begin{array}{l}\text { Irritants and/or low level } \\
\text { of chemicals/allergens }\end{array}$ \\
\hline Time-period $t$ & - & - & $0.80(0.75-0.86)$ & $0.93(0.87-0.99)$ \\
\hline $\begin{array}{l}\text { Occupational exposure ever up to } \\
\text { the previous period (ref: no) }\end{array}$ & - & - & 1 & 1 \\
\hline Known asthmagens & - & - & $149.65(95.50-234.50)$ & $23.06(13.67-38.92)$ \\
\hline $\begin{array}{l}\text { Irritants and/or low level of } \\
\text { chemicals/allergens }\end{array}$ & - & - & $4.24(2.41-7.46)$ & $58.93(35.10-98.97)$ \\
\hline $\begin{array}{l}\text { Asthma ever up to the previous } \\
\text { period }\end{array}$ & $1.08(0.78-1.49)$ & $0.90(0.60-1.36)$ & $0.74(0.50-1.12)$ & $0.59(0.37-0.93)$ \\
\hline Gender (men vs women) & $1.90(1.46-2.48)$ & $5.74(1.19-8.11)$ & $1.27(0.86-1.88)$ & $1.89(1.21-2.96)$ \\
\hline Cohort (ref: $\leq 1945)$ & 1 & 1 & 1 & 1 \\
\hline ]1945-1955] & $1.34(0.88-2.04)$ & $1.49(0.92-2.40)$ & $0.81(0.49-1.31)$ & $0.89(0.53-1.51)$ \\
\hline ]1955-1965] & $1.36(0.86-2.16)$ & $2.17(1.27-3.71)$ & $0.83(0.45-1.51)$ & $0.84(0.47-1.48)$ \\
\hline ]1965-1975] & $1.73(1.05-2.85)$ & $2.81(1.60-4.94)$ & $0.59(0.31-1.12)$ & $0.69(0.36-1.33)$ \\
\hline$>1975$ & $1.13(0.72-1.79)$ & $1.86(1.13-3.06)$ & $0.47(0.22-1.01)$ & $0.70(0.34-1.44)$ \\
\hline Age at the first hire & $0.77(0.72-0.83)$ & $0.79(0.74-0.84)$ & $1.00(0.93-1.07)$ & $0.89(0.83-0.95)$ \\
\hline $\begin{array}{l}\text { Smoking status at the previous } \\
\text { period (ref: non smoker) }\end{array}$ & 1 & 1 & 1 & 1 \\
\hline Ex-smoker & $1.46(0.47-4.49)$ & $0.79(0.18-3.43)$ & $0.60(0.36-1.01)$ & $0.87(0.49-1.56)$ \\
\hline Current smoker & $1.16(0.86-1.57)$ & $1.28(0.92-1.79)$ & $0.87(0.59-1.29)$ & $1.34(0.89-2.04)$ \\
\hline
\end{tabular}

CI, confidence interval; OR, odds-ratio.

* Multinomial logistic regression of occupational exposure at the first 5-year employment period $(s=1)$ according to factors reported for the period before first employment or time-invariant factors.

$\dagger$ Pooled multinomial logistic regression of occupational exposure at time-periods $s(s>1)$ according to factors at $s-1$ or time-invariant factors.

$\$$ Time-period included in the models as a continuous variable after checking for linearity. 